\section{The bright side}

Desmond King-Hele

Is Science Necessary? Essays on Science \& Scientists. By Max F. Perutz. E.P. Dutton, New York: 1989. Pp. 285.

$\$ 19.95$. To be published in Britain on 13 July by Barrie \& Jenkins, $£ 14.95$.

"Is scientific research the noblest pursuit of the human mind, from which springs a never-ceasing stream of beneficial discoveries, or is it a sorcerer's broom that threatens us all with destruction?" The stark alternatives set out in the opening sentence of this book nicely spotlight its theme. Max Perutz, who in 1962 shared the Nobel prize with John Kendrew for their work on haemoglobin and myoglobin, has enjoyed a splendid career buoyed by faith in the first alternative. Now he is dismayed and puzzled by the anti-scientific campaigns that make such a noise all round the world, often propagated by pressure-groups ignorant of science.

In the first half of the book he takes a cool scientific look at some of the problems facing the world, especially in food production, health and sources of energy. The second half, devoted to wartime reminiscences and essay-reviews of various books on recent scientists or advances in science, shows the human side of science and the passionate intensity of its practitioners. A chain of essays is a dangerous formula for a book: it throws a great strain on the quality of the writing, because one weak link can destroy the will to read. I am happy to say that I found this collection enthralling, right to the end, though the book's title may make scientists wince: presumably it was chosen as a bait for the anti-science activists who would greatly benefit from reading it.

Most scientists will agree with most of the conclusions in Perutz's survey of world food, health and energy. Not everyone will agree with everything however, because we all have unconscious or semiconscious biases and he is no exception. On the subject of food he tries hard to be rational and balanced, and largely succeeds. He rightly emphasizes the benefits science has brought, through highyield crops resistant to disease. What is a little lacking is the ecological dimension, and there is an air of complacency about the long-term effects of fertilizers and pesticides. On health, he brings out well the dilemma that all benefits carry some risk, and the consequent problem, that trying to eliminate all risk may stifle future advances. There are many good diagrams showing the benefits of drugs and vaccines, but one, Fig. 14, giving deaths from tuberculosis, is rather bogus because the decrease in deaths during the pre-antibiotic era is extrapolated linearly on a logarith- mic scale, thus ensuring it can never reach zero. (Replotting on a linear scale quite alters the conclusions to be drawn.)

The discussion of energy policy is generally excellent, though wave and geothermal power are not mentioned and not everyone will be happy to find Perutz championing nuclear power. If he wanted to convince sceptics, he should not have accepted so blithely the estimates of accident probabilities of "less than 1 in 10 million reactor years": such low probability estimates are worthless, and leave unanswered those who ask, "what about a crashing jumbo-jet or a hostile missile in the next 100 years?". It would be unfair to make too much of these small blemishes in a survey that is scientific, humane and appealing.

In contrast the next essay, "Enemy Alien", is inhumane and appalling. In May 1940, four years after arriving in Britain as a refugee from Austria, and having recently gained his $\mathrm{PhD}$, Perutz was rounded up as an 'enemy alien' and thrown into prison before being deported to Canada with 1,200 others in a troopship. He fared better than the previous cargo of 1,400 aliens, of whom 600 drowned when their ship was torpedoed, but the months spent in prison camps in Canada left their mark. Although Perutz never says so, I suspect that for him and for other refugeescientists imprisoned with him, including Hermann Bondi and Thomas Gold, this experience in prison has made the rest of life seem rather easy. Perhaps that is why, even in the Britain of today, they are so resilient and optimistic, convinced that culture and science will somehow prevail. Be that as it may, Perutz's book is a service to science and a pleasure to read.

Desmond King-Hele, 3 Tor Road, Farnham, Surrey GU9 7BX. UK, was formerly a Deputy Chief Scientific Officer at the Royal Aircraft Establishment, Farnborough.

\section{Togetherness}

\section{John Barrett}

Coevolution of Fungi with Plants and Animals. Edited by K. A. Pirozynski and D. L. Hawksworth. Academic: 1988 Pp.285. £35, \$68.

IT is difficult to know what to make of this collection of essays. The editors set out with the commendable objective of bringing examples of the many and varied interactions between fungi and other organisms to the attention of evolutionary biologists. But because the contributions have been written, or edited, with such a strict adherence to the proprieties of fungal terminology and taxonomy, they are likely to be tough going for nonmycologists.

As Pirozynski and Hawksworth point out in their long introductory chapter, the fact that most fungi are obligate, and often mutualistic, symbionts has led most mycologists to take coevolution for granted. In consequence, research on fungal symbioses has tended to lag behind that in other fields. The editors also confess that the number of examples that offer direct evidence of coevolutionary processes at work is very limited; they have, therefore, given the contributors a licence for 'just-so' story-telling, because without such licence "this book might not have materialised" (p. 4).

The result is a rather mixed bag of examples, ranging from instances in which there is some experimental evidence, through those with no empirical support but with testable hypotheses, all the way to those which, not to put too fine a point on it, verge on fantasy. Fortunately, most of the authors present their topics agnos- tically. For example, Evans introduces his entertaining review of entomogenous fungi with the disclaimer that "The facts are scarce and the evidence when available, is circumstantial and thus controversial. I therefore make my apologies in advance"

Coevolution can be studied at many levels. The contributions reflect this, running from studies of the 'congruence' of phylogenies of plant species and their fungal parasites (Hijwegen) down to studies at the molecular level (Pirozynski).

The value of the book is that the areas of our ignorance are laid bare. An excellent example is the case of ambrosia galls, which are formed by an interaction between a gall-forming midge, its plant host and a fungus which infects the gall and provides food for the developing midge larva. Here, one would have thought, there would be a clear prima facie case for coevolution. Yet, as one reads through Bissett and Borkent's thorough review, one begins to have doubts. Eventually these doubts are confirmed by the authors' own conclusions. Other cases of symbiotic interactions that arose through coevolution are, however, more convincing. In his excellent account of fungal endophytes of grasses, Clay presents good experimental evidence to justify his argument that coevolutionary processes have here produced a shift from parasitism to mutualism.

There is much in this volume to interest any student of coevolution. Although the mycological jargon is intimidating for the non-specialist, wading through it is probably worth the effort and will provide a rewarding insight into the evolution of fungal symbioses.

John Barrett is a Lecturer in the Department of Genetics, University of Cambridge, Downing Street, Cambridge CB2 3EH, UK. 